\title{
The evaluation of sepsis in the emergency department and its association with mortality
}

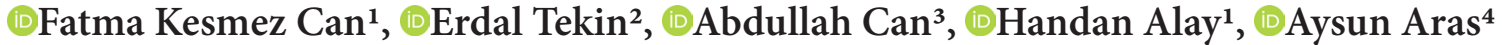 \\ ${ }^{1}$ Atatürk University, Faculty of Medicine, Department of Infectious Diseases and Clinical Microbiology, Erzurum, Turkey \\ ${ }^{2}$ Atatürk University, Faculty of Medicine, Department of Emergency Medicine, Erzurum, Turkey \\ ${ }^{3}$ University of Health Sciences Erzurum Region SUAM, Department of Anesthesiology and Reanimation, Erzurum, Turkey \\ ${ }^{4}$ Ataturk University, Department of Public Health, Erzurum, Turkey
}

Cite this article as: Kesmez Can F, Tekin E, Can A, Alay H, Aras A. The evaluation of sepsis in the emergency department and its association with mortality. J Health Sci Med 2021; 4(5): 741-745.

\begin{abstract}
Aim: Sepsis is a life-threatening organ dysfunction accompanied by a dysregulated host response to infection. Patients with sepsis may present with different clinical manifestations, and there is no gold standard diagnostic test. Early diagnosis and rapid treatment result in a decrease in sepsis-related deaths. Quick Sequential Organ Failure Assessment (qSOFA) is a scoring system used in diagnosing sepsis through a rapid evaluation at the time of initial presentation. The purpose of this study was to evaluate the relationship between qSOFA scores and mortality in patients presenting to the emergency department with suspected sepsis.

Material and Method: Seventy patients presenting to the Atatürk University Medical Faculty Emergency Department and commencing treatment with a preliminary diagnosis of sepsis between 01.12.2019 and 01.06.2020 were included in the research. Patients' qSOFA scores were calculated, and their demographic data, infection parameters and foci, the clinics to which they were admitted, and outcomes were recorded. The data were analyzed, and the relationships between qSOFA classifications and other infection parameters (CRP, procalcitonin, and lactate) and mortality were examined.

Results: Seventy percent $(n=49)$ of the 70 patients in the study were discharged, while $30 \%(n=21)$ were exitus. A statistically significant relationship was present between qSOFA scores and mortality $(\mathrm{p}<0.001)$. CRP was also significantly related to qSOFA ( $\mathrm{p}=0.003)$. Significant relationships were determined between CRP, procalcitonin and lactate and mortality $(\mathrm{p}=0.009$, $\mathrm{p}<0.001$, and $\mathrm{p}=0.009$, respectively).

Conclusion: The use of qSOFA scores at initial assessment in the emergency department appears to be a simple and rapid means of diagnosing sepsis. qSOFA levels were significantly associated with mortality. CRP, procalcitonin, and lactate levels were also associated with mortality, and CRP was significantly associated with qSOFA. Early diagnosis and treatment can be expected to reduce mortality.
\end{abstract}

Keywords: Sepsis, qSOFA, Emergency, Mortality

\section{INTRODUCTION}

Millions of individuals are diagnosed with sepsis every year. One in four cases followed-up with a diagnosis of sepsis conclude with mortality. Rapid diagnosis of sepsis and the initiation of appropriate treatment affect the disease prognosis (1). New recommendations emerged from the Third International Consensus Definitions for Sepsis and Septic Shock in 2016. Sepsis was defined as a life-threatening organ dysfunction accompanied by a dysregulated host response to infection (2). It represents the body's response to an infection. The resulting exposure leads to the release of proinflammatory and anti-inflammatory mediators. These mediators can lead to organ failure and death in sepsis by affecting endothelial damage, vascular permeability, microvascular dysfunction, and coagulopathies $(2,3)$. Clinical findings in sepsis are variables associated with the source of the infection. The most widespread infection sites leading to sepsis are the respiratory, gastrointestinal, and genitourinary systems, the skin, and soft tissue. In addition to general clinical symptoms such as fever, hypotension, tachypnea, tachycardia, confusion, anxiety, respiratory difficulty, vomiting, decreased urine output, and hypoperfusion, it can also exhibit findings localized to the region of infection $(4,5)$. 
The level of organ dysfunction occurring in sepsis is evaluated using various scoring systems based on clinical findings, laboratory data, or therapeutic interventions. Sequential Organ Failure Assessment (SOFA) is more frequently used under intensive care conditions, and requires partial arterial oxygen pressure $(\mathrm{PaO} 2)$, platelet count, and creatinine and bilirubin levels for calculation. Quick SOFA (qSOFA) is a scoring system used in diagnosing sepsis through a rapid assessment at the time of initial presentation. The Third International Consensus Definitions for Sepsis and Septic Shock agreed that qSOFA scores could be helpful to clinicians since they could be applied at the bedside in patients outside the intensive care unit and does not involve laboratory data.

A respiratory rate $\geq 22 / \mathrm{min}$, systolic blood pressure $\leq 100 \mathrm{mmHg}$, and altered mental state are evaluated, each being scored between 0 and 3 (2). There is no gold standard diagnostic test. However, early diagnosis and rapid treatment result in a decrease in sepsis-related deaths. qSOFA is used as a predictive tool calculating the risk of mortality, rather than diagnosis, at the time of first presentation. The purpose of the present study was to investigate the relationship between qSOFA and mortality and other infection parameters (CRP, procalcitonin, and lactate).

\section{MATERIAL AND METHOD}

The study was performed following receipt of approval from the Atatürk University Medical Faculty Clinical Researchs Ethics Committee (Date: 26.12.2019, Decision No: B.30.2.ATA.0.01.00/54). Seventy patients aged over 18 presenting to the Atatürk University Medical Faculty Emergency Department and commencing treatment with a preliminary diagnosis of sepsis (Based on anamnesis, state of consciousness, vital signs, laboratory parameters, and clinical status) between 01.12.2019 and 01.06.2020 were included in the research. Age, gender, accompanying diseases, vital findings on arrival, and lactate levels, procalcitonin, and lactate levels were recorded. Altered consciousness, infection foci, and the clinical to which the patient was admitted were also noted. qSOFA scores were calculated on the basis of respiration rate $\geq 22$ / min, altered mental state (a Glasgow Coma Scale score of 13 or less), and systolic blood pressure $\leq 100 \mathrm{mmHg}$. Patients were followed-up after admission in the clinic in terms of prognosis and mortality. The relationship between patients' qSOFA classifications and other infection parameters (CRP, procalcitonin, and lactate) and mortality was then examined.

\section{Statistical Analysis}

Descriptive methods were employed for demographic data. Normality of data distribution was evaluated using the Kolmogorov-Smirnov test. Data were analyzed on SPSS 23.0.0.1 software (SPSS, IBM, Armonk, NY, USA). The chi-square test and Fisher's Exact test were used in two-group comparisons. Non-parametric continuous data were compared between the groups using the Mann-Whitney $\mathrm{U}$ test. $\mathrm{p}$ values $<0.05$ were considered statistically significant.

\section{RESULTS}

Women constituted $28.6 \%(\mathrm{n}=20)$ of the 70 patients in the study. The mean age of the patients was 71.61 years $( \pm 12.1 \mathrm{SD})(\min 19, \max 92)$. Patients' other laboratory and clinical data are shown in Table 1. No correlation with mortality was observed in terms of either gender $(\mathrm{r}<0.001 \mathrm{p}=1.0)$ or age groups $(\mathrm{r}=3.630 \mathrm{p}=0.057)$. No significant correlation was also observed between either gender $(r=0.488 \mathrm{p}=0.784)$ or age groups $(r=0.363$ $\mathrm{p}=0.834$ ) and $\mathrm{qSOFA}$ scores. No exitus occurred among the patients with qSOFA scores of 1 in this research $(n=9)$. However, exitus occurred in $13.5 \%(n=5)$ of the patients with scores of 2 and in $66.7 \%(n=16)$ of those with qSOFA scores of 3 (Table 2). Patients' qSOFA scores were significantly correlated with mortality $(r=24.011$ $\mathrm{p}<0.001$ ) (Table 2).

\begin{tabular}{|c|c|c|}
\hline \multicolumn{3}{|l|}{ Clinical data } \\
\hline qSOFA & $\mathbf{n}$ & $\%$ \\
\hline 1 & 9 & 12.9 \\
\hline 2 & 37 & 52.9 \\
\hline 3 & 24 & 34.3 \\
\hline Infection focus & $\mathbf{n}$ & $\%$ \\
\hline Pulmonary infection & 35 & 50.0 \\
\hline Urinary infection & 22 & 31.4 \\
\hline Other & 13 & 18.6 \\
\hline Clinic to which admitted & $\mathbf{n}$ & $\%$ \\
\hline Intensive care & 48 & 68.6 \\
\hline Ward & 22 & 31.4 \\
\hline Mortality & $\mathbf{n}$ & $\%$ \\
\hline Discharged & 49 & 70.0 \\
\hline Exitus & 21 & 30.0 \\
\hline \multicolumn{3}{|l|}{ Laboratory data } \\
\hline CRP & $\mathbf{n}$ & $\%$ \\
\hline $5-100$ & 18 & 25.7 \\
\hline 100 or above & 52 & 74.3 \\
\hline Total & 70 & 100 \\
\hline \multicolumn{3}{|l|}{ Procalcitonin (ng/mL) } \\
\hline $0-5$ & 53 & 75.7 \\
\hline 5 or above & 17 & 24.3 \\
\hline Total & 70 & 100.0 \\
\hline \multicolumn{3}{|l|}{ Lactate $(\mathrm{mmol} / \mathrm{L})$} \\
\hline $1-1.5$ & 18 & 25.7 \\
\hline 1.5 or above & 52 & 74.3 \\
\hline Total & 70 & 100.0 \\
\hline
\end{tabular}


The most common infections were pulmonary infections at $50 \%(\mathrm{n}=35)$, followed by urinary infections at $31.4 \%$ $(n=22)$, and other infections at $18.6 \%(n=13)$ (Table 1). Analysis showed that $68.6 \%(n=48)$ of patients were admitted to the intensive care unit from the emergency department, while $31.4 \%(n=22)$ were transferred to the wards (Table 1). Exitus occurred in $41.7 \%(\mathrm{n}=20)$ of the patients admitted to the intensive care unit compared to $4.5 \%(n=1)$ of those admitted to the wards (Table 2$)$. Mortality rates differed significantly between the clinics $(\mathrm{r}=9.899 \mathrm{p}=0.002)$ (Table 1$)$.

qSOFA scores of 3 were determined in only $11.1 \%(n=2)$ of the patients with CRP values of 5-100, but in $42.3 \%$ $(n=22)$ of those with CRP values exceeding 100. qSOFA scores were significantly correlated with CRP groups $(\mathrm{r}=11.731 \mathrm{p}=0.003)$ (Table 1). No significant association was observed between qSOFA scores and procalcitonin $(\mathrm{r}=3.708 \mathrm{p}=0.157)$ or lactate $(\mathrm{r}=4.159 \mathrm{p}=0.125)$ groups (Table 3). Exitus occurred in 5.6\% $(n=1)$ of the patients with CRP values of $5-100$, and in $38.5 \%(n=20)$ of those with CRP values exceeding 100. Significant correlation was observed between the CRP groups and mortality $(\mathrm{r}=6.895 \mathrm{p}=0.009) \quad$ (Table 4). Mortality was also significantly correlated with procalcitonin $(\mathrm{r}=23.089$ $\mathrm{p}<0.001)$ and lactate $(\mathrm{r}=6.895 \mathrm{p}=0.009)$ (Table 4).

\section{DISCUSSION}

Early identification and rapid appropriate treatment of sepsis, which is linked to high morbidity and mortality, will yield good results. The present study examined the relationship between qSOFA and mortality. Men constituted $71.4 \%$ of the patients taking part. Men have also constituted more than $50 \%$ of the patients with sepsis in previous studies (6-7). This distribution has been linked to lower urinary infection rates in women due to better compliance with hygiene rules, occupation exposure in men, and the prevalence of pulmonary infections deriving from smoking (8). The mean age of the patients in research into sepsis is generally greater than 60. Lifetime accumulation of cellular damage and increased comorbid diseases also increase the tendency to sepsis in patients (9-10). The mean age of the patients with sepsis in the present study was $71.6 \pm 12.1$ years.

The most common focus of infection in this study, at $50 \%$, was the respiratory system, followed by urinary tract infection at $31.4 \%$. Chen et al. detected pneumonia in $55.8 \%$ of patients, and urinary tract infection in $20.9 \%$ (10). Our findings are compatible with the previous literature.

In the present study, $68.6 \%$ of patients were admitted to the intensive care unit, while $31.4 \%$ were followed up on the wards. Mortality rates were $41.7 \%$ in the intensive

\begin{tabular}{|c|c|c|c|c|}
\hline Q Sofa & Mortality & $\mathrm{n}=70$ & $\%$ & \multirow{6}{*}{$\begin{array}{l}r=24.011 \\
p<0.001\end{array}$} \\
\hline 1 & Discharged & 9 & 100 & \\
\hline \multirow{2}{*}{2} & Discharged & 32 & 86.5 & \\
\hline & Exitus & 5 & 13.5 & \\
\hline \multirow{2}{*}{3} & Discharged & 8 & 33.3 & \\
\hline & Exitus & 16 & 66.7 & \\
\hline Infection focus & Mortality & $n=70$ & $\%$ & \multirow{7}{*}{$\begin{array}{l}r=5.857 \\
p=0.053\end{array}$} \\
\hline \multirow{2}{*}{$\begin{array}{l}\text { Pulmonary } \\
\text { infection }\end{array}$} & Discharged & 20 & 57.1 & \\
\hline & Exitus & 15 & 42.9 & \\
\hline \multirow{2}{*}{$\begin{array}{l}\text { Urinary } \\
\text { infection }\end{array}$} & Discharged & 19 & 86.4 & \\
\hline & Exitus & 3 & 13.6 & \\
\hline \multirow{2}{*}{$\begin{array}{l}\text { Other infection } \\
\text { sites }\end{array}$} & Discharged & 10 & 76.9 & \\
\hline & Exitus & 3 & 23.1 & \\
\hline $\begin{array}{l}\text { Clinic to which } \\
\text { admitted }\end{array}$ & Mortality & $n=70$ & $\%$ & \\
\hline \multirow{2}{*}{ Intensive care } & Discharged & 28 & 58.3 & \multirow[b]{2}{*}{$r=9.899$} \\
\hline & Exitus & 20 & 41.7 & \\
\hline \multirow{2}{*}{ Ward } & Discharged & 21 & 95.5 & \multirow{2}{*}{$\mathrm{p}=0.002$} \\
\hline & Exitus & 1 & 4.5 & \\
\hline
\end{tabular}

\begin{tabular}{|c|c|c|c|c|}
\hline CRP & Q Sofa & $\mathrm{n}=70$ & $\%$ & \\
\hline \multirow{3}{*}{$5-100$} & 1 & 6 & 33.3 & \multirow[b]{3}{*}{$\mathrm{r}=11.731$} \\
\hline & 2 & 10 & 55.6 & \\
\hline & 3 & 2 & 11.1 & \\
\hline \multirow{3}{*}{100 and above } & 1 & 3 & 5.8 & \multirow{3}{*}{$\mathrm{p}=0.003$} \\
\hline & 2 & 27 & 51.9 & \\
\hline & 3 & 22 & 42.3 & \\
\hline Procalcitonin $(\mathrm{ng} / \mathrm{mL})$ & Q Sofa & $\mathrm{n}=70$ & $\%$ & \\
\hline \multirow{3}{*}{$0-5$} & 1 & 8 & 15.1 & \multirow{6}{*}{$\begin{array}{l}r=3.708 \\
p=0.157\end{array}$} \\
\hline & 2 & 30 & 56.6 & \\
\hline & 3 & 15 & 28.3 & \\
\hline \multirow{3}{*}{5 and above } & 1 & 1 & 5.9 & \\
\hline & 2 & 7 & 41.2 & \\
\hline & 3 & 9 & 52.9 & \\
\hline Lactate $(\mathrm{mmol} / \mathrm{L})$ & Q Sofa & $\mathrm{n}=70$ & $\%$ & \\
\hline \multirow{3}{*}{$1-1.5$} & 1 & 4 & 22.2 & \multirow{6}{*}{$\mathrm{r}=4.159$} \\
\hline & 2 & 11 & 61.1 & \\
\hline & 3 & 3 & 16.7 & \\
\hline \multirow{3}{*}{1.5 and above } & 1 & 5 & 9.6 & \\
\hline & 2 & 26 & 50.0 & \\
\hline & 3 & 21 & 40.4 & \\
\hline
\end{tabular}

Table 4. Correlations between patients' CRP, procalcitonin, and lactate groups and mortality

\begin{tabular}{|c|c|c|c|c|}
\hline CRP & Mortality & $\mathrm{n}=70$ & $\%$ & \\
\hline \multirow{2}{*}{$5-100$} & Discharged & 17 & 94.4 & \multirow{2}{*}{$\mathrm{r}=6.895$} \\
\hline & Exitus & 1 & 5.6 & \\
\hline \multirow{2}{*}{100 and above } & Discharged & 32 & 61.5 & \multirow{2}{*}{$\mathrm{p}=0.009$} \\
\hline & Exitus & 20 & 38.5 & \\
\hline Procalcitonin (ng/mL) & Mortality & $n=70$ & $\%$ & \\
\hline \multirow{2}{*}{$0-5$} & Discharged & 45 & 84.9 & \multirow[b]{2}{*}{$\mathrm{r}=23.089$} \\
\hline & Exitus & 8 & 15.1 & \\
\hline \multirow{2}{*}{5 and above } & Discharged & 4 & 23.5 & \multirow{2}{*}{$\mathrm{p}<0.001$} \\
\hline & Exitus & 13 & 76.5 & \\
\hline Lactate $(\mathrm{mmol} / \mathrm{L})$ & Mortality & $\mathbf{n}$ & $\%$ & \\
\hline \multirow{2}{*}{$1-1.5$} & Discharged & 17 & 94.4 & \multirow[b]{2}{*}{$\mathrm{r}=6.895$} \\
\hline & Exitus & 1 & 5.6 & \\
\hline \multirow{2}{*}{1.5 and above } & Discharged & 32 & 61.5 & \multirow{2}{*}{$\mathrm{p}=0.009$} \\
\hline & Exitus & 20 & 38.5 & \\
\hline
\end{tabular}


care unit and $4.5 \%$ on the wards. It was seen that the use of clinical, radiological and laboratory results together with the qSOFA score in the patient evaluation in the emergency department provided more accurate referrals and treatment in appropriate clinics. Seymour et al. reported a mortality rate of $4-11 \%$ for non-intensive care patients, compared to $18 \%$ for those in intensive care (11). The total mortality rate among the patients with sepsis in the present study was $30 \%$, while A charya et al. reported a rate of $40 \%$ in patients with sepsis (12), and Khwannimit et al. a rate of $45 \%$ among all patients (13).

The qSOFA score that emerged from the Third International Consensus Definitions for Sepsis and Septic Shock published in 2016 entered into use after being recommended as a good prognostic factor in predicting mortality in non-intensive care patients and admission to the intensive care unit (2). Examination of the association between qSOFA and mortality in the present study revealed no mortality in qSOFA group 1, a rate of 13.5\% in qSOFA group 2, and a rate of $66.7 \%$ in qSOFA group 3. Wang et al. investigated 477 emergency department patients diagnosed with infection and reported no difference in 28-day mortality and ICU admission rates between groups with qSOFA scores of 0 and 1 . However, an increase was reported in case of qSOFA scores higher than 1 . Mortality in patients with qSOFA $\geq 2$ was 2.5 times higher than in those with qSOFA $<2$, while the rate of admission to intensive care was 2.1 times higher (13). Another study reported qSOFA $\geq 2$ in $24 \%$ of patients with infection, with a mortality rate of $70 \%$ in that group. A 3-14-fold increase in in-hospital mortality rates was observed in patients with qSOFA $\geq 2$ (10). Freund Y. et al. reported that qSOFA exhibited $70 \%$ sensitivity and 79\% specificity. Mortality occurred in only $3 \%$ of patients with qSOFA $<2$ (15). The findings of the present study are compatible with the previous literature, and mortality increased in patients with qSOFA $\geq 2$.

Studies have emphasized lactate as an important parameter in the diagnosis and follow-up of sepsis (16). Lactate is continuously manufactured by red blood cells and certain tissue with high glycolysis rates, even at times when tissue perfusion is not impaired. The liver converts the majority of this lactate back to glucose and oxidizes the remainder. Sepsis-related hepatic dysfunction can therefore impair lactate clearance $(17,18)$.

Lactate was not used in the definition of sepsis in the Third International Consensus. It was only recommended in the definition of septic shock (2). One multi-center retrospective study no significant change in mortality or intensive care outcomes in patients with suspected sepsis at the time of admission, when qSOFA scores at presentation were reassessed with the addition of lactate $\geq 2 \mathrm{mmol} / \mathrm{L}$ to admission (11). Caseserly et al. reported that a combination of lactate $\geq 4 \mathrm{mmol} / \mathrm{L}$ and hypotension was a good predictor of prognosis. Those authors also reported that low presentation lactate levels were of low prognostic value, but that serial lactate measurements and treatment being adjusted accordingly reduced mortality rates in patients admitted to intensive care (19). Similarly, in the present study, mortality occurred in only $5.6 \%(n=1)$ of patients with lactate levels of 1-1.5 $\mathrm{mmol} / \mathrm{L}$, but in $38.5 \%(\mathrm{n}=20)$ of those with levels of 1.5 $\mathrm{mmol} / \mathrm{L}$ or above. This difference between the lactate groups in terms of mortality was statistically significant. However, no significant correlation was determined between qSOFA scores and lactate groups. The majority of research has investigated serial lactate measurement rather than lactate values at time of presentation, while post-treatment lactate values have been considered, and interpretations have been produced by combining these with other clinical data (20).

Ratherthanbeingusedasadiagnostictool,theinternational sepsis guideline recommended procalcitonin (PCT) as capable of use in shortening the antibiotic period, and in narrowing and discontinuing treatment (19) Zhenyu et al's study of 102 cases of sepsis found that PCT was correlated with mortality (21). Castelli et al. reported that PCT predicted the severity and prognosis of sepsis, and that PCT concentrations were directly related to the criticality of sepsis and positively correlated with SOFA scores (22). In the present study, mortality occurred in $15.1 \%(\mathrm{n}=8)$ of patients with PCT levels of $0-5 \mathrm{ng} / \mathrm{mL}$, but in $76.5 \%(n=13)$ of those with PCT values of $5 \mathrm{ng} /$ $\mathrm{mL}$ or above. The difference in mortality rates between the PCT groups was statistically significant. However, no significant association was determined between qSOFA scores and the PCT groups. While PCT elevation can be used as a test supporting diagnosis in patients with suspected bacterial infection, it does not discriminate between complicated and uncomplicated infections. It is not therefore sufficient by itself for use in diagnosis sepsis in the emergency department.

CRP is a well-known biomarker of infection and inflammation. Synthesis of this acute phase reactant is controlled by the liver. Although its principal disadvantage as a biomarker of sepsis in adults is low specificity, it is widely employed for screening early onset sepsis (occurring in the first $24 \mathrm{~h}$ ), since its sensitivity is generally regarded as very high in that context (23). Saeed et al. determined a mean CRP level of $102 \mathrm{mg} /$ $\mathrm{dL}$ in an exitus group, compared to $30 \mathrm{mg} / \mathrm{dL}$ in the surviving group (24). Yamamoto et al. suggested that mortality rates were four times higher in patients with CRP values higher than $150 \mathrm{mg} / \mathrm{dL}$ compared to those with values of $0-19.9 \mathrm{mg} / \mathrm{dl}(25)$. In the present study, mortality occurred in only $5.6 \%(n=1)$ of the patients with 
CRP values of 5-100, but in 38.5\% $(n=20)$ in those with values above 100. Significant differences were observed between the CRP groups in terms of qSOFA and. CRP elevation is a supportive parameter in the early diagnosis and follow-up of sepsis due to its significant relationship with qSOFA and mortality.

\section{CONCLUSION}

qSOFA is correlated with mortality, and is a simple, rapid, inexpensive, and valid method of determining sepsis risk rates in patients with suspected infection outside the intensive care unit. However, more reliable and rapid tests than qSOFA are needed in the diagnosis of sepsis.

\section{ETHICAL DECLARATIONS}

Ethics Committee Approval: The study was performed following receipt of approval from the Atatürk University Medical Faculty Clinical Researchs Ethics Committee (Date: 26.12.2019, Decision No: B.30.2.ATA.0.01.00/54).

Informed Consent: Because the study was designed retrospectively, no written informed consent form was obtained from patients.

Referee Evaluation Process: Externally peer-reviewed.

Conflict of Interest Statement: The authors have no conflicts of interest to declare.

Financial Disclosure: The authors declared that this study has received no financial support.

Author Contributions: All of the authors declare that they have all participated in the design, execution, and analysis of the paper, and that they have approved the final version.

\section{REFERENCES}

1. Liu V, Escobar GJ, Greene JD, et al. Hospital deaths in patients with sepsis from 2 independent cohorts. JAMA 2014; 312: 90-2.

2. Singer M, Deutschman CS, Seymour CW, et al. The Third International Consensus Definitions for Sepsis and Septic Shock (Sepsis-3). JAMA 2016; 315: 801-10.

3. Perman SM, Goyal M, Gaieski DF. Initial emergency department diagnosis and management of adult patients with severe sepsis and septic shock. Scand J Trauma Resusc Emerg Med 2012; 20: 41.

4. Gauer RL. Early recognition and management of sepsis in adults: the first six hours. Am Fam Physician 2013; 88: 44-53.

5. Esper AM, Moss M, Lewis CA, Nisbet R, Mannino DM, Martin GS. The role of infection and comorbidity: Factors that influence disparities in sepsis. Crit Care Med 2006; 34: 2576-82.

6. Cheng B, Li Z, Wang J, et al. Comparison of the Performance Between Sepsis-1 and Sepsis-3 in ICUs in China: A Retrospective Multicenter Study. Shock 2017; 48: 301-6.

7. Raith EP, Udy AA, Bailey M, et al. Prognostic accuracy of the SOFA score, SIRS criteria, and qSOFA score for in-hospital mortality among adults with suspected infection admitted to the intensive care unit. JAMA 2017; 317: 290-300.

8. Rhee C, Jones TM, Hamad Y, et al. Prevalence, underlying causes, and preventability of sepsis-associated mortality in US Acute Care Hospitals. JAMA Netw Open 2019; 2: e187571.
9. Milbrandt EB, Eldadah B, Nayfield S, Hadley E, Angus DC. Toward an integrated research agenda for critical illness in aging. Am J Respir Crit Care Med 2010; 182: 995-03.

10. Chen QH, Shao J, Liu WL, et al. Predictive accuracy of Sepsis-3 definitions for mortality among adult critically ill patients with suspected infection. Chin Med J (Engl) 2019; 132: 1147-53.

11. Seymour CW, Liu VX, Iwashyna TJ, et al. Assessment of clinical criteria for sepsis: for the Third International Consensus Definitions for Sepsis and Septic Shock (Sepsis-3). JAMA 2016; 315: 762-74

12. Acharya SP, Pradhan B, Marhatta MN. Application of "the Sequential Organ Failure Assessment (SOFA) score" in predicting outcome in ICU patients with SIRS. Kathmandu Univ Med J (KUMJ) 2007; 5: 475-83.

13. Khwannimit B, Bhurayanontachai R, Vattanavanit V. Comparison of the performance of SOFA, qSOFA and SIRS for predicting mortality and organ failure among sepsis patients admitted to the intensive care unit in a middle-income country. J Crit Care 2018; 44: 156-60.

14. Wang JY, Chen YX, Guo SB, Mei X, Yang P. Predictive performance of quick Sepsis-related Organ Failure Assessment for mortality and ICU admission in patients with infection at the ED. Am J Emerg Med 2016; 34: 1788-93.

15. Freund Y, Lemachatti N, Krastinova E, et al. Prognostic accuracy of Sepsis-3 criteria for in-hospital mortality among patients with suspected infection presenting to the emergency department. JAMA 2017; 317: 301-08.

16. Shankar-Hari M, Phillips GS, Levy ML, et al. Developing a new definition and assessing new clinical criteria for septic shock: For the Third International Consensus Definitions for Sepsis and Septic Shock (Sepsis-3). JAMA 2016; 315: 775-87.

17. Toffaletti JG. Blood lactate: biochemistry, laboratory methods, and clinical interpretation. Crit Rev Clin Lab Sci 1991; 28: 253-68.

18. Garrabou G, Morén C, López S, et al. The effects of sepsis on mitochondria. J Infect Dis 2012; 205: 392-400.

19. Rhodes A, Evans LE, Alhazzani W, et al. Surviving sepsis campaign: international guidelines for management of sepsis and septic shock: 2016. Intensive Care Med 2017; 43: 304-77.

20. Chertoff J, Chisum M, Simmons L, King B, Walker M, Lascano J. Prognostic utility of plasma lactate measured between 24 and 48 $\mathrm{h}$ after initiation of early goal-directed therapy in the management of sepsis, severe sepsis, and septic shock. J Intensive Care 2016; 4: 13.

21.Li Z, Wang H, Liu J, Chen B, Li G. Serum soluble triggering receptor expressed on myeloid cells-1 and procalcitonin can reflect sepsis severity and predict prognosis: a prospective cohort study. Mediators Inflamm 2014; 2014: 641039.

22. Castelli GP, Pognani C, Cita M, Stuani A, Sgarbi L, Paladini R. Procalcitonin, C-reactive protein, white blood cells and SOFA score in ICU: diagnosis and monitoring of sepsis. Minerva Anestesiol 2006; 72: 69-80.

23. Hofer N, Zacharias E, Müller W, Resch B. An update on the use of $\mathrm{C}$-reactive protein in early-onset neonatal sepsis: current insights and new tasks. Neonatology 2012; 102: 25-36.

24. Saeed K, Wilson DC, Bloos F, et al. The early identification of disease progression in patients with suspected infection presenting to the emergency department: a multi-centre derivation and validation study. Crit Care 2019; 23: 40.

25. Yamamoto S, Yamazaki S, Shimizu T, et al. Prognostic utility of serum CRP levels in combination with CURB-65 in patients with clinically suspected sepsis: a decision curve analysis BMJ Open 2015; 5: e007049. 